DOI: https://dx.doi.org/10.26808/rs.ca.i8v1.22 International Journal of Computer Application (2250-1797)

Issue 8 Volume 1, January- February 2018

\title{
Designing Regional Language Interface : A Framework for Libraries
}

\author{
Dr. Sukumar Mandal \\ Assistant Professor, Department of Library and Information Science \\ The University of Burdwan, Burdwan - 713104
}

The purpose of this research paper is to designing a interface of Bengali in Koha for libraries. Data entry is possible in Bengali language of different item types including Books, Monographs, Journals and etc. Create a new bibliographic framework for this items in different modules. Translate all the folders under the Koha modules like cataloguing, circulation, acquisition, authority control, member generation and report generation. Apart from this it also translate the OPAC interfaces in Koha for the users in libraries. This framework is very helpful for the libraries including academic, public and research libraries also. Retrieved the right information of any Bengali term which available in Koha. New windows will appear just click on the Bengali language option in Koha. It can be access from the single window based interface just click on the desktop icon.

Keywords : Koha, Bengali interface, Bibliographic framework and Transliteration

\section{Introduction}

A library is a storehouse of organized documents and information needs of the users are catered with the help of this documents. But these documents those are collected by the libraries based on a particular language are being used by the respective language users. However, the libraries sometimes purchased documents on regional or state language to meet the demands of the respective state. Therefore, a librarian faces much problems towards organizing these documents with different languages in times of integrated library system management. Hence, to manage the multilingual documents in times of library automation is a great challenge to library professionals and they are finding some means and techniques so that the language component can best manage through a FLOSS (freely open source software system) based system. Koha is a worldwide formidable open source software known to all and highly used for the purpose of library automation. The merits and inherent constituent supports of Koha can solved the problem to a greater extent. In this paper a humble approach has been attuned so as to solved the relevant problems regarding organizing the multilingual based documents of a library through an integrated approach.

Multilingual is an important aspects in our daily life situation to communicate with each other. Lot of languages are available in this World but how to managed and maintain these in libraries (Cruz...et.al, 2014). Most of the libraries are purchasing multilingual books, journals, monographs and etc. All the languages are available in mobile but not in library automation software (Ismaili, 2015). This research work tries to solved the problem of multilingual in library automation through open source tools and techniques. College libraries is playing the important role in higher education (Granell, 2015). There are many books are available in different languages like English, Bengali, Hindi and etc. Management of these multilingual resources in college libraries are important task and here this research paper has successfully solved the problem of Bengali language through open source software like Koha because its fully Unicode-compliant (Singh, Sarkar, \& Nasipuri, 2015). It is possible to managed the data both bibliographic and authority data including author, title, subject, edition and etc (Ruiz \& Chin, 2010). Students and teachers are also benefitted from the library OPAC because it can easily search the books those are available in library stack. Users were transliterate from english languages to another languages and here number of destination language 
is twenty two (Stiller, Gäde, \& Petras, 2013). This is the innovative things in integrated library management system and its known as cloud computing or information mashup. Librarians and staff can enter the bibliographic data with customized framework and this would save the time of the library staff (Jonsson \& Muhonen, 2014). Avro-phonetics and SCIM keyboard is also important tool to managed the Bengali language with the approapriate font and all the integration is to be made on Ubuntu operating system. Retrieved the right terms in Bengali language those are available in Koha bibliographic framework. This search interface is helpful for the users as well as library professionals also.

\section{Objectives}

The objectives of this research paper are explained in the following ways :

(i) To explore the multilingual interface in Koha both for librarina as well as OPAC interfaces.

(ii) To integrated the google indic transliteration in Koha OPAC with source to destination languages.

(iii) To customized the bibliographic framework for data entry of different item types.

(iv) To install and configure the Avro-Phonetics and smart common input method in Ubuntu operating system.

\section{Methodology}

The methodology of this dissertation are as follows:

(i) Installation and configuration of Koha for Bengali language by using the Ubuntu operating system.

(ii) Selection of library management open source software.

(iii) Selection of server side operating system.

(iv) Comparison of different parameters in multilingual for Bengali language

(v) Integration of Google Indic Transliteration tool in Koha OPAC.

(vi) Installation and configuration of Unicode compliant SCIM and Avro keyboard.

(vii) Selection of global recommendations like ILS-DI recommendations, IFLA-Working Group recommendations, Open Library Environment Project, Request for Comments, Request for Proposals and Service Oriented Archietecture.

\section{Customization and Configuration}

File customization is one of the important task in Koha for adding the new languages. The process of adding the Bengali language in Koha is very easy. This research paper has successfully installed and configure. First open the terminal from the option of applications and accessories in Ubuntu and here using some important commands are as follows :

sudo su

export KOHA_CONF=/etc/koha/sites/library/koha-conf.xml

export PERL5LIB=/usr/share/koha/lib

$\mathrm{cd} / \mathrm{usr} / \mathrm{share} / \mathrm{koha} / \mathrm{misc} /$ translator

perl translate install ben-IN

After finishing this tasks required to change the language from the option of system preferences and here change the language just click on the check box in Bengali language and then logout and login Koha. Then required the Zebra configuration in Koha for regional language searching both for librarian as well as OPAC interfaces. Open the file from the terminal by using the leafpad or gedit texteditor as follows:

sudo gedit /etc/koha/zebradb/etc/default.idx 
Here find the important line of Zebradb "charmap word-phrase-utf.chr" and comment it by inserting a \# symbol. It also configure the same line appeared in next paragraph of Zebra indexing language for easy searching of Bengali language in Koha. This is also an important to configure the and add the line below the commented lines, icuchain words-icu.xml. Run the command by using the terminal for rebuild the zebra indexing in Koha sudo koha-rebuild-zebra -v -f library.

\section{Development of Multilingual Environment for Library}

In general, the API of the middle layer should follow the Open - Closed principle, which states that software entities (modules) should be open for extensions, but closed to modifications. Being the system software, IM frameworks make extensive use of services provide by modern operating system (Shokouhi \& Si, 2011). There are many languages are available in six cluster like integrated library system cluster, content management system cluster, college communication interaction cluster, federated search system cluster, learning content management system cluster and digital media archiving cluster (Mudawwar, 1997). These all cluster are managed through SCIM input method for solve the multilingual problem in college libraries under the university of Burdwan. SCIM input tools are easily managed the languages, fonts and script in table -1 for developing the multilingual facilities both from staff-client as well as user interfaces and this table shows the 48 languages that can easily managed through scim tool.

\begin{tabular}{|c|c|c|c|c|c|}
\hline $\mathrm{S} 1$ & Name of Languages & Sl. & Name of Languages & S1. & Name of Languages \\
\hline 1 & Amharic ${ }^{41}$ & 21 & Hindi $^{13}$ & 41 & Tamil $^{33}$ \\
\hline 2 & Arabic ${ }^{42}$ & 22 & Japanese $^{14}$ & 42 & Telugu $^{34}$ \\
\hline 3 & Armenian $^{43}$ & 23 & Kannada $^{15}$ & 43 & Thai $^{35}$ \\
\hline 4 & Assamese $^{1}$ & 24 & Kazakh $^{16}$ & 44 & Tibetan $^{36}$ \\
\hline 5 & Bengali $^{2}$ & 25 & Korean ${ }^{17}$ & 45 & Uighur; Uyghur ${ }^{37}$ \\
\hline 6 & Burmese $^{44}$ & 26 & Lao $^{18}$ & 46 & $\mathrm{Urdu}^{38}$ \\
\hline 7 & Central Khmer ${ }^{45}$ & 27 & Malayalam $^{19}$ & 47 & Vietnamese $^{39}$ \\
\hline 8 & Chamic Languages ${ }^{46}$ & 28 & Marathi $^{20}$ & 48 & Other ${ }^{40}$ \\
\hline 9 & Chinese $^{3}$ & 29 & Nepali $^{21}$ & & \\
\hline 10 & Croatian $^{47}$ & 30 & Oriya $^{22}$ & & \\
\hline 11 & Danish $^{48}$ & 31 & Panjabi; Punjabi ${ }^{23}$ & & \\
\hline 12 & Divehi;Dhivehi ; Maldivian $^{4}$ & 32 & Persian $^{24}$ & & \\
\hline 13 & English $^{5}$ & 33 & Russian $^{25}$ & & \\
\hline 14 & Esperanto $^{6}$ & 34 & Sanskrit ${ }^{26}$ & & \\
\hline 15 & French $^{7}$ & 35 & Serbian $^{27}$ & & \\
\hline 16 & Georgian $^{8}$ & 36 & Sindhi $^{28}$ & & \\
\hline 17 & Greek, Ancient (to 1453) ${ }^{9}$ & 37 & Sinhala; Sinhalese ${ }^{29}$ & & \\
\hline 18 & Greek, Modern (1453-) ${ }^{10}$ & 38 & Slovak $^{30}$ & & \\
\hline 19 & Gujarati $^{11}$ & 39 & Swedish $^{31}$ & & \\
\hline 20 & Hebrew ${ }^{12}$ & 40 & Tai Languages ${ }^{32}$ & & \\
\hline
\end{tabular}

Table - 1: Multilingual languages represents through open source software 
DOI: https://dx.doi.org/10.26808/rs.ca.i8v1.22 International Journal of Computer Application (2250-1797) Issue 8 Volume 1, January- February 2018

Different fonts and scripts are represents in the following way:-

1. Phonetic, inscript and itrans ; 2. Itrans, Unijay, Prabhat, Inscript, phonetic

3. Py, Pinyin, quick, tonepy, canjie and bopomofo; 4. Phonetic; 5. Ispell

6. q-sistemo, h-sistemo, h-fundamente, vi-sistemo, $\mathrm{x}$-sistemo and plena

7. Azerty; 8. kbd; 9. Mizuochi; 10. Kbd; 11. Itrans, inscript and phonetic; 12. Kbd

13. Inscript, itrans, typewriter, phonetic and remington

14. Trycode, anthy and tcode; 15 . Inscript, itrans and kgp

16. Kbd and Arabic; 17. Han2 and romaja; 18. Irt and kbd

19. Inscript, Mozhi, itrans and Swanalekha

20. Itrans, inscript and phonetic; 21 . Rom and trad; 22. Itrans, phonetic and inscript

23. Jhelum, itrans, phonetic and inscript; 24. Isiri

25. Yawarty, phonetic, kbd and translit; 26. Harvard-kyoto; 27. Kbd; 28. Inscript;

29. Trans, samanala, wijesekhara-preedit, wijesekara, phonetic-dynamic, phonetic-static

30. Kbd ; 31. Post; 32. Sonla-kbd;

33. Typewriter, phonetic, itrans, lk-renganathan, inscript, tamil99

34. Rts, pothana, inscripts, itrans and apple; 35. Pattachote, tis 820 and kesmanee

36. Ewts, tcre and Wylie; 37. Kbd; 38. Phonetic

39. Tcvn, vni, han, nomvni, nomtelex, telex and viqr

40. Compose, latin-post, rfc1345, latex, latn-pre, syrc-phonetic and Unicode

41. Sera; 42. Kbd; 43. Kbd; 44. Kbd; 45. Yannis; 46. Kbd; 47. Kbd; 48. Post;

The updated SCIM Input Method provides efficient input facilities for the Bengali language in the Ubuntu operating system. This is the whole process of customizing and using the input software and is believed to be useful for anybody interested to develop a SCIM Input Method for their respective languages.All the languages are to be appeared in data entry interfaces for domain specific cluster and also see their fonts by seamless integration in Ubuntu operating system.

\section{Bengali Interface in Koha}

The Fgiure - 1reveals that the Bengali interface in Koha administration and this will appear after translate the all modules files effectively and efficiently in the integrated library system cluster. This interface is helpful only for the college librarians but not the users. It also affect the library professionals those are interested in open source software.

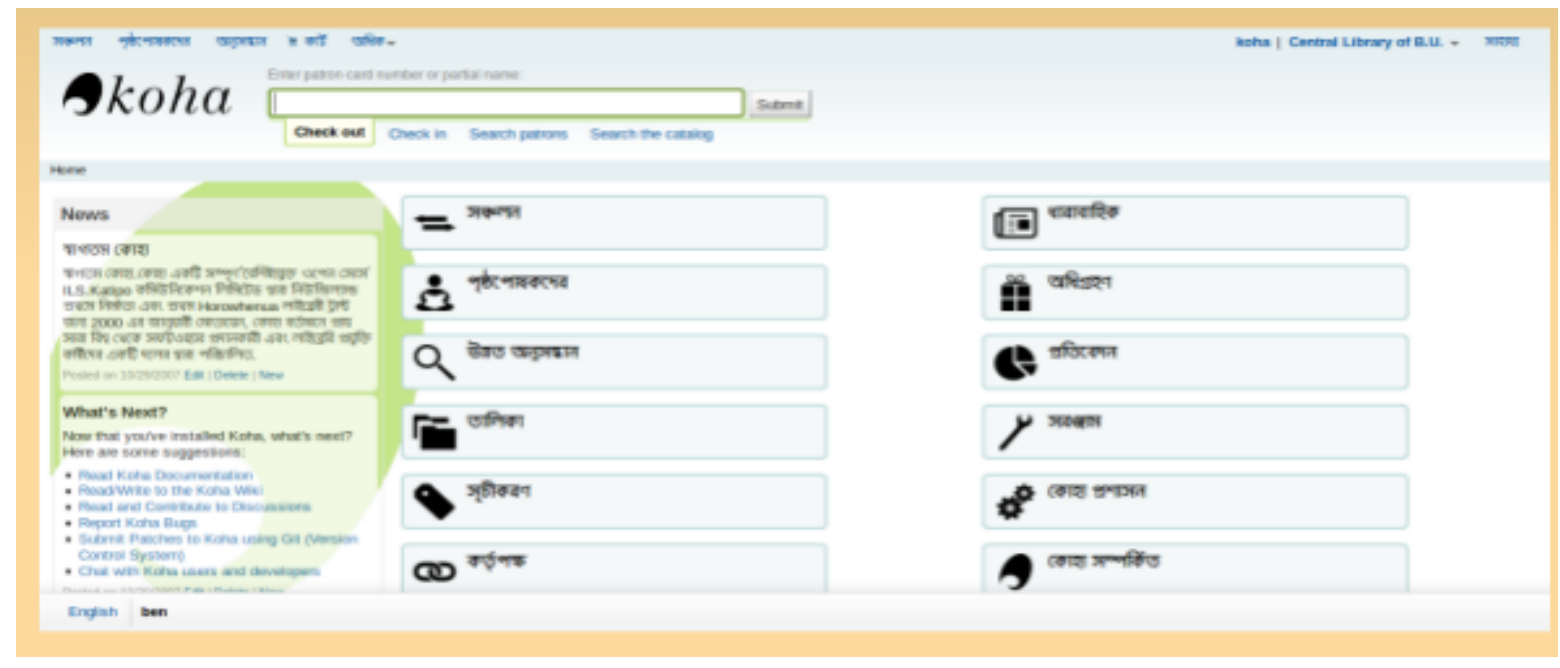

Figure -1 : Bengali interface in Koha

\subsection{Bibliographic Data Entry Interface}

The data entry is also possible by using avro phonetic keyboard on Ubuntu interface. In this way the Koha - 3.X is support the Ubuntu Linux operating system so it can easily entered the data 
in Bengali through avro phonetic (See Figure - 2) nd it can visible in staff client and OPAC interface. Simultaneously it can also managed the multilingual resources and also their fonts. Now, SCIM input method is an important tools in Ubuntu operating system which can easily managed the Bengali Script in College libraries under the University of Burdwan for designing the integrated library management system and retrieval system.

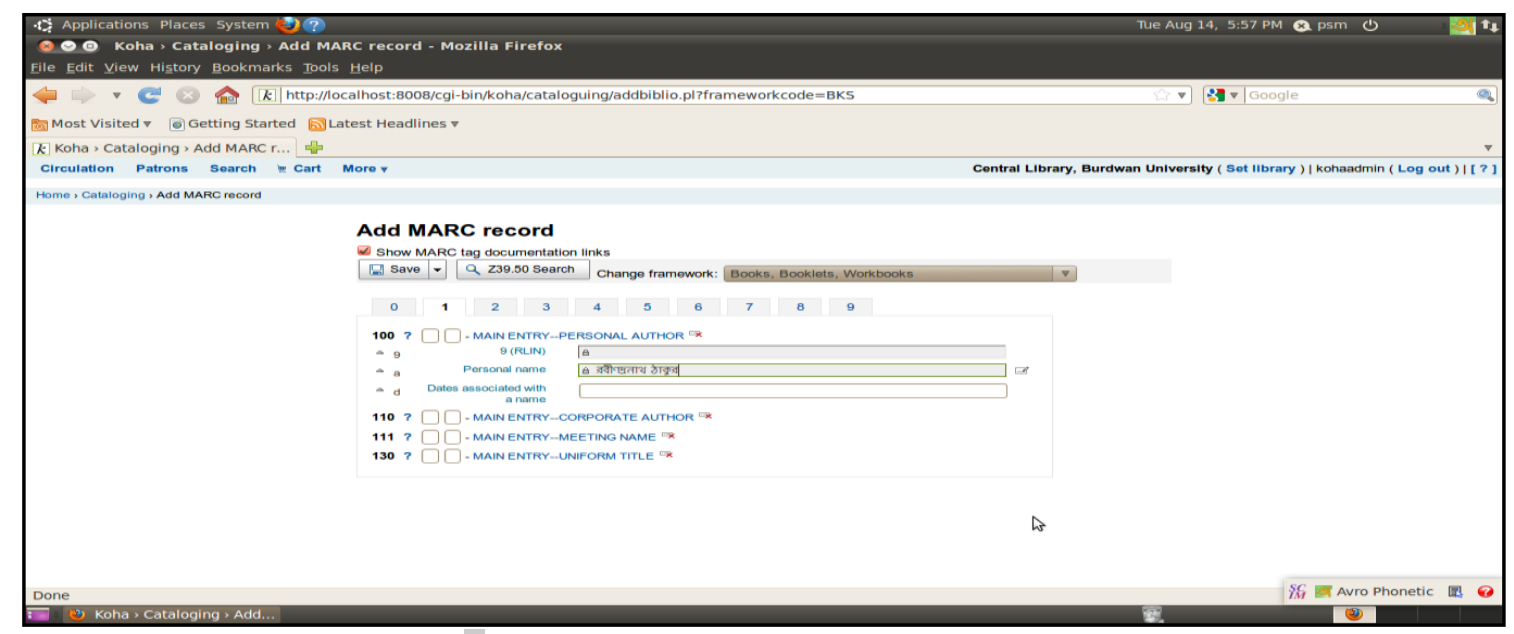

Figure - 2: Bibliographic data entry interface in Koha

\subsection{Search Results of Regional Language}

College libraries can easily search the regional languages of books and other library materials. The number of books are count in a single window of different wise and branch wise also. Regional language setup is start from the Koha administration under global system preferences. Search results display in different sets and in different formats such as normal view, ISBD and MARC view. Each an every records is easily searching both the librarian as well as OPAC interfaces. The search results are described in the next chapter of features of the integrated framework due to all the important results with access point discussed in this section. Now, the Figure -3 is represents the search results of regional language and here regional language is Bengali because here most of the people speak in Bengali language. This framework is more helpful to the target libraries.

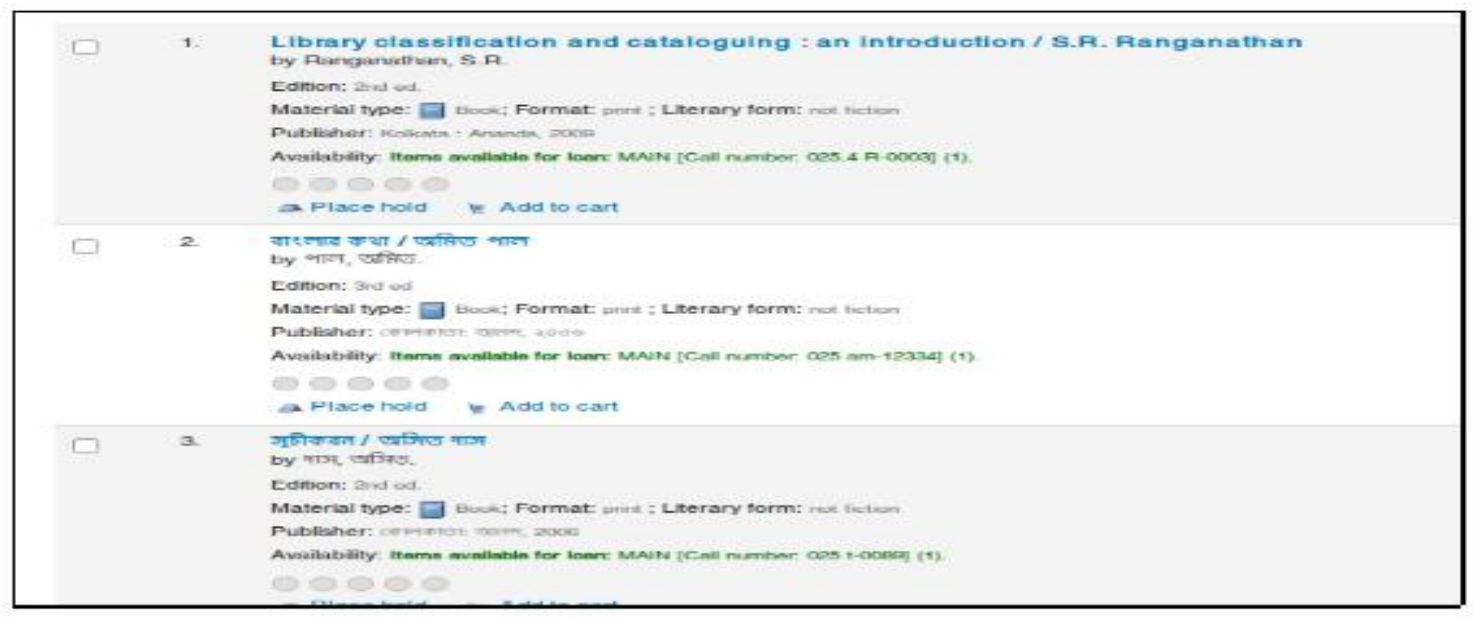

Figure -3 : Search results in Bengali language 
DOI: https://dx.doi.org/10.26808/rs.ca.i8v1.22 International Journal of Computer Application (2250-1797) Issue 8 Volume 1, January- February 2018

\subsection{Google Indic Transliteration in Koha OPAC}

Users and librarians can managed the twenty two languages from the library OPAC in Koha including Amharic, Arabic, Bengali, Persian, Greek, Gujarati, Hebrew, Hindi, Kannada, Malayalam, Marathi, Nepali, Oriya, Punjabi, Russian, Sanskrit, Serbian, Sinhala, Tamil, Telugu, Tigrinya and Urdu (Yuwono \& Lee, 1997). All the languages are to be access through Google input tool and this developing made on Ubuntu operating system due to its higher security rather than Windows operating system. But this google input tool support both the operating system yet this research work select only Ubuntu operating system. Koha is fully support the Unicode based standards for manage the multilingual resources and all the language code available in online environment to access from the library OPAC pinpointedly, exhaustively and expeditously. But here internet connection is mandatory for translating the resources from source language to destination languages (Brice, 2015). The figure -4 will represents the transliteration is possible from one language to another languages and it can convert in type word languages (Viles \& French, 1995). If ignore the transliteration from the Koha library OPAC press the ctrl+g and again type in English for search the documents to retrieved it from the specific library. Here English is default languages because this file known as java base googleindictransliteration file. After testing the Google Indic Transliteration in Koha OPAC the all language will appear and translate it from English to Bengali and also other 22 languages. This is the most easy process to integrate in Koha OPAC (Figure - 4) for managed the multilingual transliteration. The results of translate from English to Bengali and to ignore the transliterate press ctrl+g. This is the most innovative features towards next level automated and digital library system.

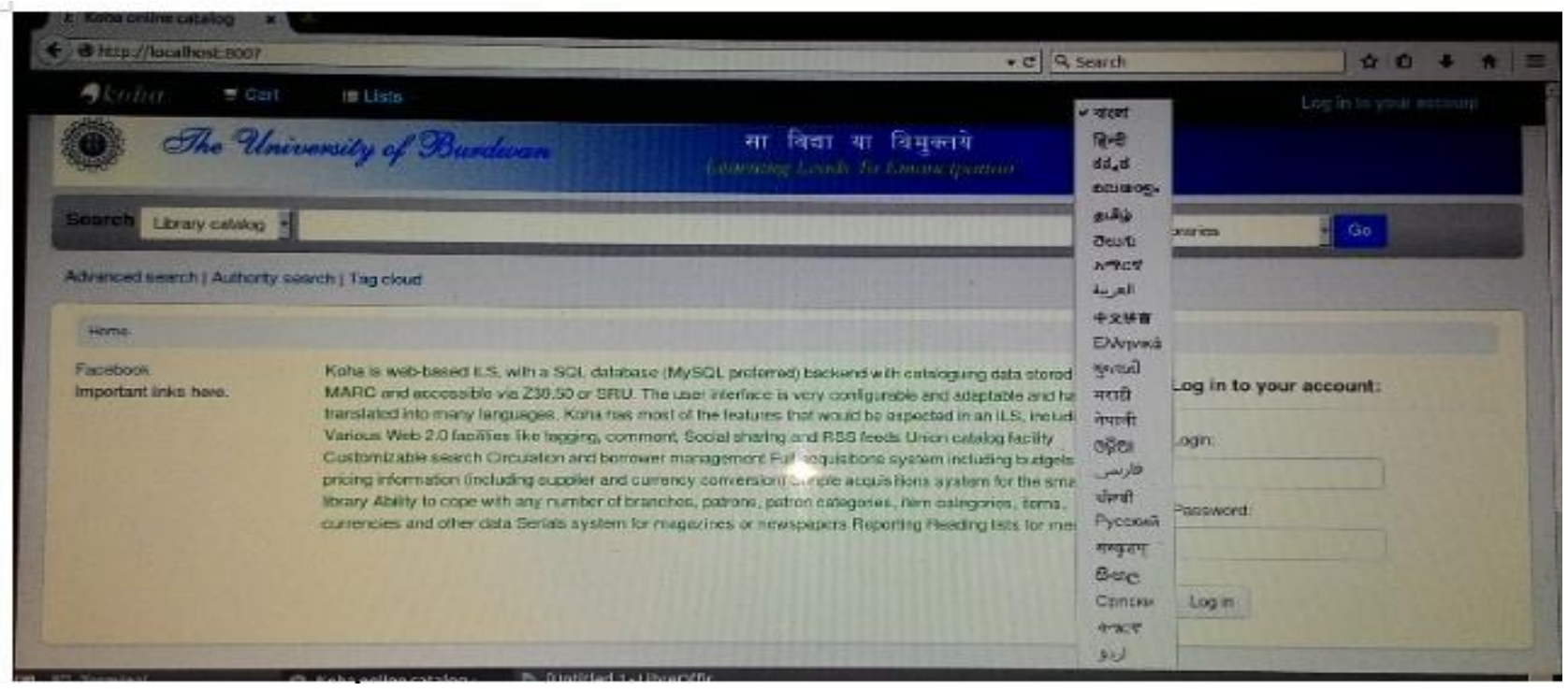

Figure - 4: Google Indic Trnansliteration interface in Koha OPAC

The most of the college libraries are facing problem in Bengali transliteration but this research work try to solve this problem through Google Indic Transliteration tool in Koha OPAC interface. The transliteration model also performed better when compared to Google Indic transliteration. But the fact is that the Google system is designed for general transliteration whereas the model presented here is trained exclusively for Indian names and places. It is concluded that this transliteration model is applicable for the languages which have the same alpha-phonetic sequence in both source and target languages. This transliteration framework is designed on the basis of global recommendations for designing and developing the college libraries under the University of Burdwan. 
DOI: https://dx.doi.org/10.26808/rs.ca.i8v1.22 International Journal of Computer Application (2250-1797) Issue 8 Volume 1, January- February 2018

\section{Findings}

The findings of this research papaer are explained as follows:

(i)It is possible to managed the bibliographic records in Bengali language.

(ii)It is possible to integrate the avro keyboard in Koha on Ubuntu operating system.

(iii)Export and import the bibliographic records in Bengali language from one system to another.

(iv)Easily upgrade and maintain the Koha by using the open source solution manul.

(v)Housekeeping operations and information retrieval is also possible for the users as well as library professionals.

(vi)Access the Koha interfaces from the single window based interfaces.

\section{Conclusion}

This Indian labguage framework can be easily implement in any library for managing the regional language where the library is situated and the librarians can easily implement and use the OPAC interface in their libraries. The library today is being revolutionized with advancement of information technology and new tools and techniques. The future librarian may be designated as cybrarian or cyber librarian, as librarian has to provide information service from a large number of documents which are published in digital form and available in Internet. Spelling correction is also possible in each words because its appear nearest spelling and here select the correct spelling during typing. Obviously, it can save the time of the librarians and college users. Intergrated of Virtual keyboard in Koha OPAC only by clicking on mouse. Now a days significant number of documents are now available in the Internet as free of cost. So, the college librarians may find some benefits if a computer system provided to the library in the areas of domain specific cluster. So a library may think to reorient its activities with the help of modern technologies. It may not be far away when a large number of students will demand computerized service from a college library. Virtual keyboards for almost all the standards of Indian languages are to be accessed from the online environment. Thus any language can be managed by using this interface for libraries. The originality of this dissertation work is very important in libraries because they can easily managed the Bengali language both for librarian as well as OPAC interfaces in Koha. Retrieved the right information against in one term from the Koha search interfaces. Finally create the ZIP file for easy installation and configuration of all the libraries. Data entry in Bengali language is managed by the customized framework in Koha for libraries.

\section{References}

Brice, A. E. (2015). Multilingual Language Development. In J. D. Wright (Ed.), International Encyclopedia of the Social \& Behavioral Sciences (Second Edition) (Second Edition, pp. 57 - 64). Oxford: Elsevier. Retrieved from http://www.Sciencedirect.com/science/article/ pii/B 9780080970868231267

Cruz, F. L., Troyano, J. A., Pontes, B., \& Ortega, F. J. (2014). Building layered, multilingual sentiment lexicons at synset and lemma levels. Expert Systems with Applications, 41(13), 5984 - 5994. http://doi.org/http://dx.doi.org /10.1016/j.es wa.2014.04.005

Granell, X. (2015). 9 - From \{PLEs\} to PLWEs: a Multilingual Information Management System. In X. Granell (Ed.), Multilingual Information Management (pp. 157 - 163). Oxford: Chandos Publishing. Retrieved from http://www.sciencedirect. com/science/article/pii/B97 81843347712000093

Ismaili, M. (2015). Teaching English in a Multilingual Setting. Procedia - Social and Behavioral Sciences, 199, 189 - 195. http://doi.org/http://dx.doi. Org/10 .10 16/ j.sbspro.2015.07.505

Jonsson, C., \& Muhonen, A. (2014). Multilingual repertoires and the relocalization of manga in digital media. Discourse, Context \& Media, 4-5, 87 - 100. http://doi.org/http://dx.doi.org 
DOI: https://dx.doi.org/10.26808/rs.ca.i8v1.22 International Journal of Computer Application (2250-1797) Issue 8 Volume 1, January- February 2018

/10.1016/j.dcm.2014.05.002

Mudawwar, Muhammad F. (1997). Multicode: A Truly Multilingual Approach to Text Encoding. Computer, 30 (4), 37-43, April 1997.

Ruiz, M. E., \& Chin, P. (2010). Users' seeking behavior and multilingual image tags. Proceedings of the American Society for Information Science and Technology, 47, 1, 1-2.

Shokouhi, M., \& Si, L. (2011). Federated search. Boston: Now Publishers.

Singh, P. K., Sarkar, R., \& Nasipuri, M. (2015). Offline Script Identification from multilingual Indic-script documents: A state-of-the-art. Computer Science Review, 15-16, 1 - 28. http://doi.org/http://dx.doi.org/10.1016/j.cosrev.2014.12.001

Stiller, J., Gäde, M., Petras, V. (2013). Multilingual Access to Digital Libraries: The Europeana Use Case. Information - Wissenschaft \& Praxis, 64 (2-3), 86 - 95.

Viles, C. L. \& French, J. C. (1995). Dissemination of collection wide information in a distributed 157information retrieval system. In Proceedings of the 18 th Annual International ACM SIGIR Conference on Research and Development in Information Retrieval. ACM.

Yuwono, B. \& Lee, D. L. (1997). Server ranking for distributed text retrieval systems on the Internet. In Proceedings of the 5th Annual International Conference on Database Systems for Advanced Applications. (pp. 41-49). World Scientific Press. 